\title{
Preface: Homework
}

Not far from where I now live, beyond the Scranton grid, along Boulevard Avenue, on the other side of Green Ridge Assisted Living and Mike's Scrap Yard, stands the Lackawanna Recycling Center, which occupies ground of the former Marvine colliery, on whose culm dump, once site of a fire that burned blue and red for years, sprawls a U.S. Armed Forces Reserve complex.

During the 1950s, my grandfather, a resident of West Side in Carbondale, worked as a conductor for the Delaware and Hudson Railroad, which hauled Marvine colliery coal. Although he had to start work in Wilkes-Barre, he refused to drive a car or to take a train, so every time he had to report to the rail yards, my widowed mother drove him, which meant managing two toddlers for the hour trip, one way, through a nest of narrow streets. Traveling a straight line to Oneonta, New York, and coming back the next day, the D \& H train rumbled through Carbondale, passing a few blocks from their house. On the day of his return, he told my mother, she was to listen for the train's whistle at the Seventh Avenue crossing, pile everyone into the car, and time her arrival in Wilkes-Barre with the train's easing into the station. They practiced this commute while a mine fire burned beneath their home, threatening their displacement.

Over the Moosic Mountains, in Wayne County, we heated the farmhouse with anthracite, which came, like as not, from a Hudson Coal Company mine. A kid keeping the furnace alive, I nightly fed its fire with baskets of "rice," which I dumped over the lip of a fifty-five-gallon drum attached to the stoker. The ashes I piled against the cellar's fieldstone foundation, banking them for use on snow-filled mornings when the milk truck couldn't make the hill.

I write about land use. The first example above suggests the ironies of spatial and temporal orientation, the second nods to how our patterns-in this case, fuel and travel-wear on others, and the third acknowledges the interconnectionsfor good and ill-between very different lands. To write about land use is to 
write about how different types of work create these ironies, patterns, and interconnections. Evidence of land-shaping work surfaces repeatedly in my home region's literature and history, in my own interactions with these lands, and in my native places' cultural and economic forms-the organization of farms and mines, for example.

I offer here my homework, a record both physical and textual. Whatever I do or read becomes, no matter how briefly, a part of my ordering of the world. Even when I read or labor alone, I'm in the company of another mind; I participate in conversations about the world that extend before and after me. With reading and lived experience so interdependent, I overlay in this book texts and contexts, near and far. I keep returning to the local, though, because good work dwells in the details, always.

Here and There refuses to back away from any kind of knowing, especially narrative. A lived experience, land use unfolds in place, over time. In revealing familiar tensions within this unfolding, I trespass freely across genres, chronologies, and disciplines. Anecdotes and footnotes may compete for your consideration in Here and There, but each asks only that you pay attention. 